\title{
The Effects of Lithuanian School-Based Positive Youth Development Program on Positive and Problem Outcomes
}

\author{
Ilona Kajokiené ${ }^{1}$, Saule Raižienè ${ }^{1}$, Ingrida Gabrialavičiūtè ${ }^{1}$, \\ Inga Truskauskaitè-Kunevičienè $\dot{1}^{1} \&$ Renata Garckija ${ }^{1}$ \\ ${ }^{1}$ Mykolas Romeris University, Vilnius, Lithuania \\ Correspondence: Ilona Kajokienė, Mykolas Romeris University, Vilnius, Lithuania. Tel: 370-65-57-0944. \\ E-mail: ilonakajokiene@yahoo.com
}

Received: September 2, 2015

Accepted: September 26, 2015

Online Published: October 8, 2015

doi:10.5539/ijps.v7n4p8

URL: http://dx.doi.org/10.5539/ijps.v7n4p8

\begin{abstract}
With the present study, we aimed to evaluate the effectiveness of youth development program implemented in one of the high schools in Vilnius, Lithuania. 351 ninth to tenth grade students participated in an 8 weeks long Youth Development (YD) program with the 4 month long optional volunteering possibilities and were compared to 262 students in a demographically and academically similar control high school. Both the participants of the YD program and the controls were evaluated three times during one academic year. Pre-test, post-test and follow-up evaluations in an experimental and control group were conducted. The results showed limited time effect on connection. The change of contribution, internalizing and externalizing problems to the direction opposite than hypothesized were found over the one year for both groups.
\end{abstract}

Keywords: positive youth development, the Five Cs, contribution, internalizing problems, externalizing problems, school-based youth development program

\section{Introduction}

\subsection{The Framework of Positive Youth Development}

During recent years, a noticeable increase in theory and research regarding the Positive Youth Development (PYD) has been documented (Lerner, 2004a, 2004b; Lerner et al., 2005). Interest in positive youth development emerged as a contrast with a traditional focus on the deficit of youth that dominated in the field of human development up to the end of XX century. Traditionally, adolescence has been considered a time of "storm and stress", with universal, biologically based changes that inevitably drive adolescents to a period of emotional and physical conflict and stress (Hall, 1904; in Lerner et al., 2005). Even as recently as twenty-five years ago and even in programs purportedly focused on promoting positive youth development, a predominant emphasis in the youth development field continued to be a reliance on the deficit model of youth and on defining PYD as the absence of adolescent problem behaviours (Benson, 2003). Youth who was seen as manifesting behaviour indicative of positive development was depicted as someone who was not taking drugs or using alcohol, not engaging in unsafe sex, and not participating in crime or violence. Such descriptions were predicated on the assumption that children are "broken" or in danger of becoming broken (Benson, 2003), and thus were regarded as "problems to be managed" (Roth \& Brooks-Gunn, 2003a, 2003b).

The roots of PYD perspective are found in developmental systems viewpoint (e.g., Lerner, 2004b), a paradigm uniting several theories with a focus on holism, interactionism and plasticity. Contrary to deficit views of human behaviour and development, it offers an optimistic theoretical frame for studying adolescent development (Mueller, Phelps, Bowers, Agans, Urban, \& Lerner, 2011). Developmental systems theories indicate that youth should be studied not in isolation, but rather as the product of the bidirectional relationship between the individual and his or her environment (Mueller et al., 2011). This viewpoint emphasizes that the fundamental process of human development involves mutually influential relations between the developing individual and the multiple levels of ecology of human development, represented as individual $\leftrightarrow$ context relations. In this perspective development is seen as a synthesis of variables from all levels of organization within the ecology of human development (ranging from biological through cultural and historical). These levels of organization are interdependent, as the development arises from the multidirectional, reciprocal, synthesizing relations among all aspects of the ecological 
system (Overton, 2014). The interdependent or fused system of individual $\leftrightarrow$ context relations that provides each person with the potential for change or relative plasticity across the lifespan constitutes a fundamental strength of each person. The fused developmental system provides also a potential for change not just in people but as well in the contexts within which individuals develop. This latter potential means that families, neighborhoods, and cultures are also relatively plastic and that the level of resources - or developmental assets - that they possess at any point in time may also be altered across history. Contextual strengths and assets in support of positive development may be envisioned within the terms suggested by Benson (2003), as the community "nutrients" for healthy and positive development. These assets can be grown, aligned, and realigned to improve the circumstances of human development. Therefore, developmental systems theory legitimizes the concept of positive human development.

Based on the ideas of developmental systems paradigm positive youth development theory suggests that when personal resources of adolescents are aligned with environmental assets, the adolescents are on a thriving developmental path (Lerner, 2004a). This exemplary adolescents' development has been theorized to involve competence, confidence, caring, character and (positive social) connections - the Five Cs (Benson, 2003; Lerner, 2004a). It is also proposed, that there is an inverse relationship between positive and negative developmental outcomes (Lerner, 2004a, 2004b). In other words, youth with better-developed positive characteristics tends to manifest less or not at all emotional or behaviour problems. In addition, both theory and the results of numerous researchers suggest that when the Five Cs is present in a young person's development, there is the emergence of "sixth C": contribution to self, family, community, and civil society (Lerner, 2004a; Lerner, Fisher, \& Weinberg, 2000). It is proposed that both the Five Cs and contribution are most likely to develop from participation in exemplary community youth developmental programs (Lerner, 2004a, 2004b; Roth \& Brooks-Gunn, 2003a, 2003b).

\subsection{Fostering Positive Youth Development through Program Participation}

Scales et al. (2000; see also Blum, 2003; Roth \& Brooks-Gunn, 2003a, 2003b) have identified participation in youth programs as the key asset linked to exemplary positive development, or thriving. Therefore, school-based intervention programs, in general, and youth developmental programs, in particular, provide additional to usual contextual opportunities to participants to develop more competencies that will enable them to grow further. Youth development programs stimulate skill-building, exploration of novelties and help adolescents to enhance the resilience and to thrive. Inter alia these intervention means are also oriented to help youth to avoid numerous behaviour problems in future. Inasmuch as teens need better preparation for challenges that helps them to stand the social demand for success, and productivity in adulthood. Many school-based educational and interventional instruments are directed to optimize the development of children. The school has been identified as a valuable context for the intervention programs as a place of learning and structural activities (Masia-Warner, Nangle, \& Hansen, 2006; Fagan \& Catalano, 2013; Forman, Olin, Hoagwood, Crowe, \& Saka, 2009; Greenberg et al., 2001).

Summarizing, the positive development programs have to draw attention to specific youth needs in a physically and psychologically safe environment. While trying to reveal, "what works" in positive youth developmental programs, Catalano with his colleagues (2004) has also stressed three ultimate elements for effective programs for positive development in America's schools. They mentioned (a) opportunities for participation and leadership, (b) development of life-skills, and (c) caring adult-youth relationship. Elements defined by Catalano et al. (2004) are similar to those identified by Roth and Brooks-Gunn (2003a), who uncovered defining characteristics of youth development programs as always having youth-centered, knowledge-centered, care-centered goals, atmosphere and activities. Lerner (2004a) in his review has summarized features of best practice of developmental program, as "Big Three", which involves opportunities for youth participation and leadership, and development of life skills within the context of a sustained and caring adult-youth relationship (2004a). Blum (2003) also noted that comprehensive programs offer adults as models to young people through whom they could learn how to form relationships or learn to learn problems solving. Rhodes and Roffman (2003) noted that these new non-parental relationships outside the school could improve peer and parental relationships, academic achievement, and self-concept. Therefore, durable youth participation, adult mentorship, and skill building are the bedrocks upon which effective positive youth development programs must be built (Lerner, 2004a).

\subsection{The Effectiveness of PYD Programs on the Five Cs and Contribution}

The authors (Eccles \& Gootman, 2002; Roth \& Brooks-Gunn, 2003a, 2003b) indicate that participation in YD programs falling into the concept of PYD is likely to result in a competent, confident, and caring youth, who has character and positive social connections. Although there are numerous attempts to evaluate PYD program effectiveness (e.g., Catalano et al., 2004), the attempts to empirically test whether youth development programs 
stimulate changes in the Five Cs and/or contribution are limited. The very first cross sectional efforts to prove relationship between program participation and PYD (measured as the Five Cs) in early adolescence (Lerner et al., 2005) yielded insignificant results, but the relationship between program participation and contribution was found. The other cross-sectional study has proven that the level of Fair participation (the part of 4-H programming activities) positively predicts character, caring and contribution (Arnold, Meinhold, Skubinna, \& Ashton, 2007). Some other unpublished research, based on program evaluation reports, show, that 4-H Horse program participants are tended toward the high end of the range for each of the Five Cs and contribution subscales (Arnold \& Nott, 2010a) and 4-H Youth voice: Youth choice healthy living program was proven to be effective in fostering all the Five Cs as well as contribution (Arnold \& Nott, 2010b). However, this conclusion was made regardless some serious methodological limitations. The quasi-experimental attempt to evaluate the 4-H Youth participatory evaluation and Youth community action training (YPE/YCAT) programs on the Five Cs of PYD and contribution (White, 2009) failed to find any in-group time effects or inter-group effects. The longitudinal 4-H study (Lerner \& Lerner, 2013) found significant mean differences in PYD (measured as the Five Cs), comparing program participants vs non-participants only in grades 8 and 11. Differences of contribution were found stable in grades 7 through 12. This data indicates the relationship between program participation and contribution.

To summarize, the PYD programs evaluations on the Five Cs and contribution are limited to 4-H project, which means, that all published studies were conducted in US; therefore, the findings are hard to generalize in other cultural contexts. In addition, most of the studies using the Five Cs and contribution as program effectiveness indicators are poorly designed for the quality evaluation and provide insufficient data. Furthermore, the findings are inconsistent and the only quasi-experimental study found no expected program effect, although practitioners claim for this program to be highly beneficial. These limitations encourage further exploration of the Five Cs and contribution as PYD program effectiveness indicators in other cultural contexts.

\subsection{The Effectiveness of PYD Programs on Problem Outcomes}

Not only the increase in positive outcomes but also reduction of youth problems stands in conceptual model of positive youth development as expected outcome of effective youth development programs (e.g., Lerner, Bowers, Geldhof, Gestsdóttir, \& DeSouza, 2012). Eichas et al. (2001) found that The Changing Lives Program (short-term, PYD intervention implemented in the USA as Miami project) is effective in decreasing internalizing problems directly and externalizing problems indirectly (through decrease of internalizing problems). The Chinese PYD program PATHS was also proven to be effective in decreasing substance use and delinquent behaviour among adolescents (Shek \& Yu, 2012) and this appeared to be a long-term effect, based on comprehensive data of well-designed study. However, the 4-H program participants did not differ compared to non-participants in risk/problem behaviour (Lerner \& Lerner, 2013).

To sum up, there is some strong empirical evidence for PYD interventions to be effective in reducing youth problems and it makes internalizing and externalizing problems good indicator for PYD program effectiveness. However, some inconsistency of findings based on well-known and successful programs was discovered and this encourages further exploration of these constructs in different cultural context.

\subsection{The Lithuanian Context for PYD Program Implementation}

Benson (2003) and Lerner (2004b) suggest, that human development depends on cultural context. The Republic of Lithuania is situated on the east coast of the Baltic Sea and has a population of 2,972,900 (Statistics Lithuania, 2013). In 2011, children aged 0-14 years made up $15 \%$ of the country's population, compared with $20 \%$ in 2000 . A population ageing is reflected in these numbers. In 2010, age-standardized mortality from all causes in Lithuania was 951 per 100,000 of the population-the second-highest among the 27 EU Member States (European Commission, 2013). Mortality from suicides and alcohol-related causes was the highest in the EU. In 2011, the share of people at risk of poverty and social exclusion was 33.4\% (compared with the EU-27 average of 24.2\%) (European Commission, 2013).

Countries with lower GDP, including Lithuania, were associated with decrease of mental well-being, comparing with countries with higher GDP (such as Sweden, Belgium, Austria, and Netherlands) (Gallup Organization, 2009). A foregoing survey revealed that girls in all Europe are even at a higher risk of impaired well-being. KIDSCREEN-10 index revealed, that 15-17 aged adolescents showed the poorest overall mental well-being and school functioning, comparing to other age groups in Europe (Erhart \& Ravens-Sieberer, 2008).

Because of increased migration rates, the proportions of children growing up in a nuclear family composed of a biological father and mother-intact family-has reduced over the past decade in Lithuania. These transformations may have affected child rearing and socialization of children. Such family is less able to control the self-destructive behaviour of the children, such as smoking, alcohol and drugs intake (Zaborskis \& Sirvyte, 
2015). An increasing trend in smoking among school children in Lithuania has been observed: the prevalence in 15 year olds who smoke at least once a week has increased from $27 \%$ to $34 \%$ among boys and from $11 \%$ to $21 \%$ among girls between 2001-2002 and 2009-2010 (Currie et al., 2004, 2012). The proportion of 13 year olds who have been drunk at least twice has decreased in boys from $25 \%$ to $20 \%$ and increased in girls from $14 \%$ to $17 \%$ between 2001-2002 and 2009-2010 (Currie et al., 2004, 2012). Children in Lithuania show the lowest subjective happiness rates in Europe (Currie et al., 2010). However, according to Pilkauskaite-Valickiene (2015), a positive youth development is positively associated with life satisfaction and contribution.

Our study aims to evaluate the effect of school-based Lithuanian Youth Development (YD) program on positive and problem outcomes. We hypothesized that participation in the program would increase positive outcomes (competence, confidence, caring, character, connection, and contribution) and decrees negative ones (internalizing and externalizing problem behaviours).

\section{Method}

\subsection{Participants}

The data used in this study come from an on-going longitudinal research project "Mechanism of promoting positive youth development in the context of socio-economical transformations (POSIDEV)", conducted in Lithuania. The subjects included 627 (43.1\% females) of the students who attended 9 and 10 grades in 2014 autumn at two high schools in Vilnius. School one was chosen as experimental, school two - as control. The age of subjects ranged from $14-16\left(\mathrm{M}_{\text {age }}=15.26, \mathrm{SD}_{\text {age }}=.66\right)$. Of those $96.8 \%$ who answered about their ethnicity, $90 \%$ identified as Lithuanians.

The recruited subjects were assigned to the experimental and the control group by the school that they attended. The subjects in the experimental and control groups did not differ in age $(\mathrm{t}(604)=.465, \mathrm{p}>.05)$ and gender $(\chi 2(1)$ $=.951, \mathrm{p}>.05)$. For the current study, we used data from 613 students participated in the pre-test assessment (participation rate 97.8\%). Of the 613 participants, 351 (57.3\%) were from the intervention group, while 262 (42.7\%) from the control group. An attrition rate in the post-test was $6.1 \%$ and $9.3 \%$ in the follow-up assessment.

\subsection{Program Description}

The short-term school-based YD program was created by the researchers of the longitudinal research project POSIDEV. It was designed to develop the internal strengths of youth and promote their prosocial involvement in the community service. The program lasted for 2 months and consisted of 8 (45 minutes duration) weekly class sessions. Each session was aimed at enhancing from one to three of the Five Cs of positive development and incorporated individual and group activities (such as group discussions, role-plays, individual reflections) that provide youth with opportunities to explore and nurture their talents, practice new skills and gain a sense on personal or group recognition. The topics of the program sessions and their correspondence to the goals of promoting the Five Cs are presented in Table 1. When students in the experimental group had program sessions, students in the control group had regular classes. After completing the program, experimental group students were introduced to various local volunteering opportunities (animal shelters, Caritas run services, child care centers, providing help in organizing public events, etc.) and could start volunteering if they chose to.

The program was delivered by 28 university student volunteers. Before the program started, they participated in two-days training to ensure the uniformity of the program delivery. They were also supervised once a week by the research team members during the program implementation period.

\subsection{Measures}

The Positive Youth Development Inventory (PYDI) (Arnold, Nott, \& Meinhold, 2012) was used to measure positive youth development. The PYDI was developed as an outcome measure of youth development programs. The instrument follows the Five Cs model of youth development, by measuring competence (14 items, e.g., "I am a creative person"), character (9 items, e.g., "It is important that others can count on me"), connection (8 items, e.g., "I have a wide circle of friends"), caring ( 8 items, e.g., "When there is a need I offer assistance whenever I can"), and confidence (9 items, e.g., "I feel good about my scholastic ability"). Each item is rated on a four-point scale: 1-Strongly disagree, 2-Disagree, 3-Agree, and 4-Strongly agree. Mean scale scores were computed for each subscale, higher scores indicate higher levels of the Five Cs. In the current study, Cronbach's alphas ranged across the three time points from .74 to .78 for competence, from .68 to .79 to for character, from .66 to .77 for connection, from .81 to .86 for caring, from .75 to .80 for confidence. The Lithuanian version of the questionnaire was prepared by researchers from the POSIDEV project team. The comparison of translated Lithuanian version with the back-translation to the original did not reveal any inconsistencies. The Lithuanian version was also piloted which led to additional clarification of some items. 
Table 1. List of the sessions of Lithuanian youth development program and their correspondence to the goals of promoting the Five Cs of positive development

\begin{tabular}{lll}
\hline $\begin{array}{l}\text { Session } \\
\text { No. }\end{array}$ & Topic of the session & Positive youth development goals \\
\hline 1 & I can be open to a new experience. & Confidence, Character, Connection \\
2 & I can learn about my strengths. & Character, Confidence \\
3 & I can cherish my connections with others. & Connection \\
4 & I can understand my and other people's feelings. & Competence \\
5 & I can survive in difficult situations. & Competence, Character, Caring \\
6 & I can see life as a meaningful experience. & Confidence, Character, Competence \\
7 & I can share. & Caring, Competence, Connection \\
8 & I can be a volunteer. & Caring, Character \\
\hline
\end{tabular}

Contribution was measured with the Three-dimensional Contribution Scale (Truskauskaite-Kunevičienè, Kaniušonytė, \& Žukauskienė, 2014) developed for POSIDEV project. This measure consists of 15 items, measuring three aspects of contribution: contribution to self (5 items, e.g., "I like to try different activities"), contribution to family (5 items, e.g., "I often show interest in how my family members are doing"), and contribution to community (5 items, e.g., "I'm engaged in volunteering activities"). The items are scored on a 5 -point scale ranging from 1 (strongly disagree) to 5 (strongly agree). Mean scale scores were computed for each subscale so that higher scores indicate higher contribution. In the current study, Cronbach's alphas were .71, .75, and .83 for contribution so self, $.86, .86$ and .70 for contribution to family, $.83, .85$ and .86 for contribution to community, at pre-test, post-test, and follow-up, respectively.

The items from four scales (Anxiety/Depressiveness, Withdrawal/Depressiveness, Rule breaking and Aggressive behaviour) of the YSR (Achenbach \& Rescorla, 2001) were used. 9 items (e.g., "I am nervous or tense",) assessed internalizing problems and 8 items assessed externalizing problems (e.g., "I disobey at school"). For each item, the respondents used a 3-point Likert-type scale to rate how well the item describes them during the past 6 months: not true (0), somewhat or sometimes true (1), and very true or often true (2). A higher mean score of the items represents a higher level of internalizing or externalizing problem behaviours. Cronbach's alphas ranged across the three-time points from .81 to .85 for internalizing problems and from .77 to .80 for externalizing problems.

\subsection{Procedures}

The quasi-experimental design of this study consisted of a pre-test, post-test and follow-up measures in experimental and control groups. All 9-10th-grade students from school one were assigned to an experimental group, and all 9-10th-grade students from school two were assigned to control group. Schools were selected for the study based on their similarity of the structure and the neighborhood. Both schools were gymnasiums, i.e. they only have grades from 9 to 12 . They were both located in areas of Vilnius with similar neighborhood characteristics. All participants were asked to fill out a questionnaire three times: before the program started (pre-test in September 2014), after the program ended (post-test in January 2015), and 4 months after the program ended (follow-up in May 2015). Each school was visited before the first assessment took place in order to discuss the dates of the assessments. Parents were informed about the study by the letter. Parents were asked to contact the school or investigators if they did not want their children to participate. Before each assessment, adolescents were reminded about the purpose of the study and that participation was voluntary. Questionnaires were administered in the class by the researchers during regular class hours. It took from 20 to 45 minutes to complete 
the questionnaires of each assessment. Students who were absent on the days of data collection were contacted in the next one or two weeks by the school personnel and asked to fill out the questionnaire.

\section{Results}

A 2 (group: experimental and control) x 3 (measurement point: pre-test, post-test and follow-up) two-way mixed design analyses of variance (ANOVA) were conducted to see the effect of participation in the program on positive youth development, contribution, and problem behaviours.

Table 2. Means and standard deviations for the subscales of positive youth development

Positive youth development

\begin{tabular}{|c|c|c|c|c|c|c|c|}
\hline \multirow[b]{3}{*}{ Competence } & \multirow[t]{2}{*}{$\mathrm{N}$} & \multicolumn{2}{|c|}{ Pre-test } & \multicolumn{2}{|c|}{ Post-test } & \multicolumn{2}{|c|}{ Follow-up } \\
\hline & & M & SD & M & SD & M & SD \\
\hline & & & & & & & \\
\hline Experimental group & 302 & 3.01 & .31 & 3.03 & .33 & 3.04 & .38 \\
\hline Control group & 238 & 3.02 & .34 & 3.01 & .36 & 3.01 & .38 \\
\hline \multicolumn{8}{|l|}{ Character } \\
\hline Experimental group & 302 & 3.09 & .35 & 3.13 & .38 & 3.14 & .39 \\
\hline Control group & 239 & 3.13 & .38 & 3.12 & .42 & 3.12 & .40 \\
\hline \multicolumn{8}{|l|}{ Connection } \\
\hline Experimental group & 305 & 3.19 & .39 & 3.15 & .43 & 3.13 & .48 \\
\hline Control group & 240 & 3.20 & .41 & 3.15 & .41 & 3.12 & .42 \\
\hline \multicolumn{8}{|l|}{ Caring } \\
\hline Experimental group & 305 & 3.13 & .42 & 3.12 & .45 & 3.12 & .42 \\
\hline Control group & 240 & 3.15 & .44 & 3.14 & .46 & 3.11 & .49 \\
\hline \multicolumn{8}{|l|}{ Confidence } \\
\hline Experimental group & 304 & 3.07 & .40 & 3.05 & .42 & 3.07 & .41 \\
\hline Control group & 240 & 3.04 & .41 & 3.04 & .42 & 2.99 & .44 \\
\hline
\end{tabular}

Means and standard deviations for positive development variables at different time points are reported in Table 2. The mixed design analyses of variance revealed a significant main effect of measurement point on connection $\left(\mathrm{F}(1.949,1058.571)=7.218, \mathrm{p}<0.01, \eta_{p}{ }^{2}=.013\right)$. Scores of connection decreased in time for both groups. No significant main effects of group and measurement point on competence, character, caring and confidence were found. Means and standard deviations for contribution at different time points are reported in Table 3.

The mixed design analyses of variance revealed significant main effects of measurement point on contribution to $\operatorname{self}\left(\mathrm{F}(1.942,1009.606)=7.065, \mathrm{p}<0.01, \eta_{p}{ }^{2}=.013\right)$, contribution to family $(\mathrm{F}(1.755,910.770)=3.285, \mathrm{p}<$ $\left.0.05, \eta_{p}{ }^{2}=.006\right)$, contribution to community $\left(\mathrm{F}(2,1034)=10.239, \mathrm{p}<0.001, \eta_{p}{ }^{2}=.019\right)$. Scores of all aspects of contribution decreased for both groups between pre-test and post-test and increased between the post-test and follow-up. There were no significant interactions between group and measurement point. Means and standard deviations for problem behaviours at different time points are reported in Table 4.

The mixed design analyses of variance revealed a significant main effect of measurement point on internalizing problems $\left(\mathrm{F}(2,1080)=2400.615, \mathrm{p}<0.001, \eta_{p}{ }^{2}=.816\right)$ and externalizing problems $(\mathrm{F}(2,1082)=3162.352, \mathrm{p}<$ $0.001, \eta_{p}{ }^{2}=.854$. The interaction between the group and measurement point was significant for internalizing problems $\left(\mathrm{F}(2,1080)=3.365, \mathrm{p}<0.05, \eta_{p}{ }^{2}=.006\right.$. A small increase of both types of problem behaviours was observed in both groups at post-test measurement time and a considerable increase at follow-up measurement time. The control group showed a larger increase in internalizing problems than experimental group. There was no significant interaction between group and measurement point for externalizing problems. 
Table 3. Means and standard deviations for the subscales of contribution

\section{Contribution}

\begin{tabular}{|c|c|c|c|c|c|c|c|}
\hline \multirow[b]{3}{*}{ Contribution to self } & \multirow[t]{2}{*}{$\mathrm{N}$} & \multicolumn{2}{|c|}{ Pre-test } & \multicolumn{2}{|c|}{ Post-test } & \multicolumn{2}{|c|}{ Follow-up } \\
\hline & & M & SD & M & SD & M & SD \\
\hline & \\
\hline Experimental group & 289 & 3.79 & .57 & 3.69 & .65 & 3.72 & .67 \\
\hline Control group & 233 & 3.84 & .64 & 3.73 & .65 & 3.82 & .72 \\
\hline \multicolumn{8}{|c|}{ Contribution to family } \\
\hline Experimental group & 288 & 3.60 & .75 & 3.53 & .78 & 3.58 & .79 \\
\hline Control group & 233 & 3.55 & .88 & 3.57 & .82 & 3.70 & 1.09 \\
\hline \multicolumn{8}{|l|}{$\begin{array}{l}\text { Contribution to } \\
\text { community }\end{array}$} \\
\hline Experimental group & 287 & 3.14 & .76 & 2.90 & .77 & 2.98 & .81 \\
\hline Control group & 232 & 3.07 & .79 & 2.98 & .86 & 3.01 & .90 \\
\hline
\end{tabular}

Table 4. Means and standard deviations for the subscales of problems behaviours

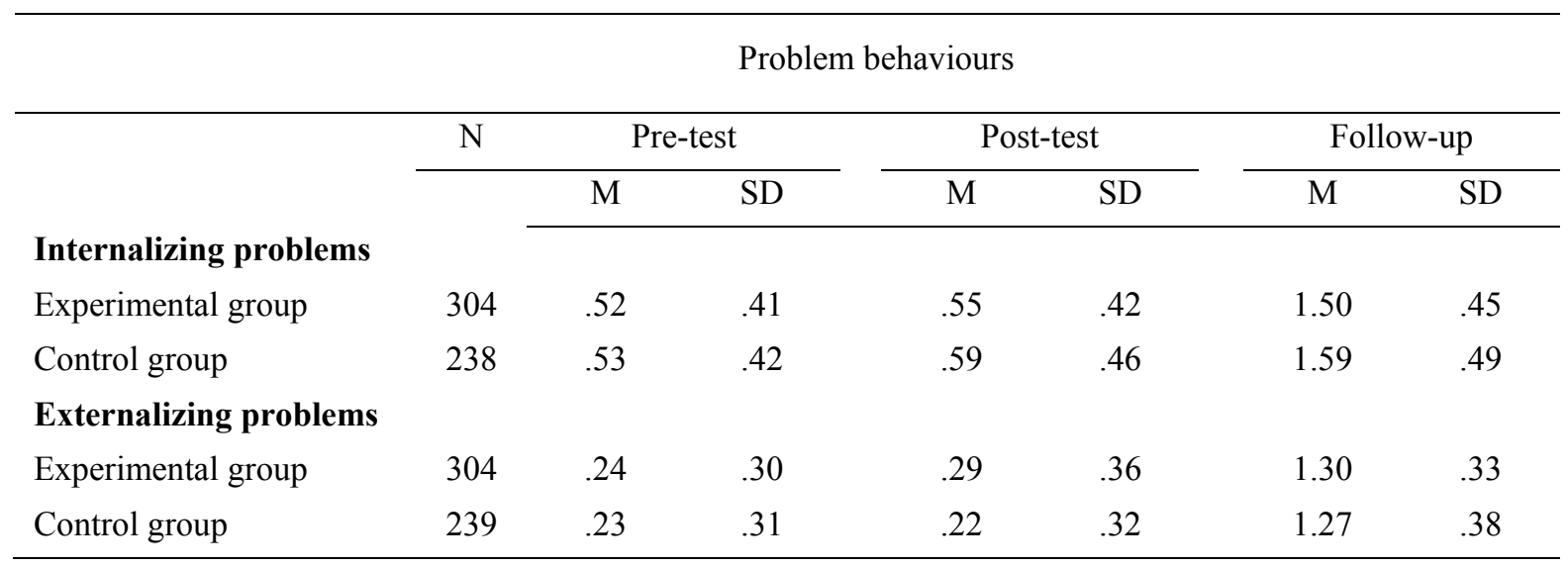

\section{Discussion}

The aim of the current study was to evaluate the effectiveness of school-based Lithuanian Youth Development (YD) program. The results of quasi-experimental study revealed no program effect on positive and problem outcomes. There were no differences between experimental and control groups for the Five Cs, contribution and internalizing and externalizing problems. However, several time effects were found, indicating, that some positive and negative outcomes change over time. Connection and all the three aspects of contribution decreased and internalizing and externalizing problems increased over time for both groups.

After the literature review (Gabrialavičiūtè, Raižienè, Truskauskaitė-Kunevičienè, \& Garckija, 2014), the Lithuanian YD program was created based on the Five Cs framework of positive youth development perspective (Lerner et al., 2005). Therefore, we expected that this program would have an impact on individual $\leftrightarrow$ context relationship and accordingly will foster the Five Cs (confidence, competence, caring, connection, character) and contribution. The fact, that no expected effect was found could be attributable to the Five Cs as suitable outcome measures for program outcome effectiveness. Despite the theoretical considerations of the effect of PYD programs on the Five Cs, in fact, only few empirical studies use broadly defined Five Cs as PYD outcome measures of programs effectiveness. The common practice is to measure specific indicators of PYD, such as self-efficacy, resilience, spirituality (Sheck \& Sun, 2012), positive identity (Eichas et al., 2010) or self-regulation (Mueller et al., 2011). Moreover, similarly to the results of the current study, those that used the Five Cs as outcome measures and a quasi-experimental design, found no expected effect (White, 2009). Therefore, we suppose that the Five Cs' 
categories could be too broad for conceptualizing the outcomes of YD programs. As suggested by Schwartz, Pantin, Coatswoth and Szapocznik (2007) more culturally sensitive indicators of PYD, measuring program effectiveness, could be considered.

The unexpected decreases of connection and contribution and an increase of problem behaviours could be explained by a timeline of data collection. All the measurement time-points were distributed within one academic year. The workload of the students usually increases over time within a year; therefore, post-test and follow-up measurements considered with the most stressful periods of academic year, when adolescents' attention could be exclusively directed toward academic achievement. Possibly the measurement time-points were too frequent. We suggest continuing the follow-up measures to test for later tendencies.

The absence of program effect could also be explained with reference to the Lithuanian YD program's design peculiarities. The program was oriented toward an extensive goal — promotion of prosocial behaviour - and the idea of volunteering were stated many times during the program implementation as desirable but not obligatory outcome of program participation. However, volunteering in Lithuania so far has neither long tradition nor general social value. This could have led to some disallowance from the side of adolescents which possibly caused non-valid filling of questionnaires at least from some of the participants. This study was the first quasi-experimental attempt to evaluate YD program in Lithuania, therefore, we suggest future YD programs should correspond to adolescents' needs more closely and the process of implementation the program should be reconsidered.

There could be several other cultural reasons why the immediate effect of the program was not found. Possibly, the program was not able interfere the relatively stable emotional atmosphere at school, which could be described through asymmetrical relationships between pupils and teachers with little respect from adults to youth. Such kind of relationships are seen as normal as the consequence of the long history of soviet occupation and refers to the phenomenon called "homo-sovieticus" (Bistrickas \& Kociunas, 1989). In fact, the peer relations are damaged as well, as the rates of school-bullying behaviors are the one of the highest in EU countries (Zaborskis \& Vareikiene, 2007). Such historical and cultural wounds couldn't be healed so quickly (Bistrickas \& Kociunas, 1989). Therefore, the current intervention program may be one of the multiple efforts needed to change this long lasting situation.

For the future research, we suggest testing gender and socio-economic status as moderators of program effectiveness. In addition, we assume that further data analysis using a different approach (e.g., person-centered approach) could bring new insights for the results of the current study.

\section{Conclusion}

The preliminary analysis had showed no direct effects on group differences concerning the school-based PYD program efficacy in Lithuania. Paradoxically, some limited time effect on connection and all the three aspects of contribution, internalizing and externalizing problems to the other than hypothesized direction were found over the one year for both groups.

\section{Acknowledgements}

This research is/was funded by the European Social Fund under the Global Grant measure, VP1-3.1-ŠMM-07-K-02-008.

\section{References}

Achenbach, T. M., \& Rescorla, L. A. (2001). Manual for the ASEBA School-Age Forms \& Profiles. Burlington, VT: University of Vermont Research Center for Children, Youth, and Families.

Arnold, M. E., \& Nott, B. D. (2010a). Oregon State 4-H Horse Program Evaluation Youth Report.

Arnold, M. E., \& Nott, B. D. (2010b). 4-H Youth Voice: Youth Choice.

Arnold, M. E., Meinhold, J. L., Skubinna, T., \& Ashton, C. (2007). The motivation for and developmental benefits of youth participation in county 4-H fairs: A pilot study. Journal of Extension, 45(6).

Benson, P. L. (2003). Developmental assets and asset-building community: Conceptual and empirical foundations. In R. M. Lerner, \& P. L. Benson (Eds.), Developmental assets and asset-building communities: Implications for research, policy, and practice (pp. 19-43). http://dx.doi.org/ 10.1007/978-1-4615-0091-9_2

Bistrickas, R., \& Kociunas, R. (1989). "Homo sovieticus”. Sietynas, 2, 8-16.

Blum, R. W. (2003). Positive youth development: A strategy for improving health. In F. Jacobs, D. Wertlieb, \& R. M. Lerner (Eds.), Enhancing the life chances of youth and families: Public service systems and public policy 
perspectives. Volume 2 of Handbook of applied developmental science: Promoting positive child, adolescent, and family development through research, policies, and programs (pp. 237-252). Thousand Oaks, CA: Sage Publications.

Catalano, R. F., Berglund, M. L., Ryan, J., Lonczak, H. S., \& Hawkins, J. D. (2004). Positive Youth Development in the United States: Research Findings on Evaluations of Positive Youth Development Programs. The Annals of the American academy of political and social science, 591(1), 98-124. http://dx.doi.org/10.1177/0002716203260102

Currie, C., Griebler, R., Inchley, J., Theunissen, A., Molcho, M., Samdal, O., \& Dür, W. (2010). Health Behaviour in School-aged Children (HBSC) study protocol: Background, methodology and mandatory items for the 2009/10 survey. Edinburgh: CAHRU \& Vienna: LBIHPR.

Currie, C., Zanotti, C., Morgan, A., Currie, D., de Looze, M., Roberts, Ch., ... Barnekow, W. (2004). Young people's health in context. Health Behaviour in School-aged Children (HBSC) study: International report from 2001/2002 survey. In Health Policy for Children and Adolescents (No. 4). Copenhagen, WHO Regional Office for Europe.

Currie, C., Zanotti, C., Morgan, A., Currie, D., de Looze, M., Roberts, Ch., ... Barnekow, W. (2012). Social determinants of health and well-being among young people. Health Behaviour in School-aged Children (HBSC) study: International report from the 2009/2010 survey. In Health Policy for Children and Adolescents (No. 6). Copenhagen, WHO Regional Office for Europe.

Eccles, J., \& Gootman, J. A. (Eds.). (2002). Community programs to promote youth development. Washington, DC: National Academy Press.

Eichas, K., Albrecht, R. E., Garcia, A. J., Ritchie, R. A., Varela, A., Garcia, A., ... Kurtines, W. M. (2010). Mediators of positive youth development intervention change: Promoting change in positive and problem outcomes? Child \& Youth Care forum, 39(4), 211-237. http://dx.doi.org/10.1007/s10566-010-9103-9

Erhart, M., \& Ravens-Sieberer, U. (2008). First results of the Flash Eurobarometer Survey 246 on Mental Health in Children/Young people. In Meeting of the Group of Governmental Experts on Mental Health and Well-being. European Commision, Health \& Consumer DG, C4-Health determinants, Luxemburg.

European Commission. Eurostat statistical database [online database]. Brussels, European Commission. Retrieved from http://epp.eurostat.ec.europa.eu/portal/page/portal/eurostat/home/ accessed $20 \mathrm{Sptember}$, 2013.

Fagan, A. A., \& Catalano, R. F. (2013). What works in youth violence prevention: A review of the literature. Research on Social Work Practice, 23(2), 141-156. http://dx.doi.org/10.1177/1049731512465899

Forman, S. G., Olin, S. S., Hoagwood, K. E., Crowe, M., \& Saka, N. (2009). Evidence-based intervention in schools: Developers' views on implementation barriers and facilitators. School Mental Health, 1, 26-36. http://dx.doi.org/10.1007/s12310-008-9002-5

Gabrialavičiūtè, I., Raižienė, S., Truskauskaitè-Kunevičienė, I., \& Garckija, R. (2014). Youth Development Programs in Lithuania: Prevention and Positive Youth Development. International Journal of Psychological Studies, 6(3), 13-23. http://dx.doi.org/10.5539/ijps.v6n3p13

Gallup Organization. (2009). Parents' views on the mental health of their child. In Analytical report. Flash EB Series \#246.

Greenberg, M. T., Domitrovich, C., \& Bumbarger, B. (2001). Preventing mental disorders in school-age children: A Review of the Effectiveness of Prevention Programs. In Center for Mental Health Services (CMHS) Substance Abuse, Mental Health Services Administration. U.S. Department of Health and Human Services. Retrieved from http://www.prevention.psu.edu/media/prc/files/MentalDisordersfullreport.pdf

Lerner, R. M. (2004a). Programs promoting positive youth development and civil society. In R. M. Lerner (Ed.), Liberty: Thriving and civic engagement among American youth (pp. 109-143). Thousand Oaks, CA: Sage. http://dx.doi.org/10.4135/9781452233581.n6

Lerner, R. M. (2004b). Diversity in individual context relations as the basis for positive development across the lifespan: A developmental systems perspective for theory, research, and application. Research in Human Development, 1(4), 327-346. http://dx.doi.org/10.1207/s15427617rhd0104_5 
Lerner, R. M., \& Lerner, J. V. (2013). The positive development of youth: Comprehensive findings from the $4 H$ study of positive youth development. Medford, MA: Institute for Applied Research in Youth Development, Tufts University.

Lerner, R. M., Bowers, E. P., Geldhof, G. J., Gestsdóttir, S., \& DeSouza, L. (2012). Promoting positive youth development in the face of contextual changes and challenges: The roles of individual strengths and ecological assets. New Directions for Youth Development, 135, 119-128. http://dx.doi.org/10.1002/yd.20034

Lerner, R. M., Fisher, C. B., \& Weinberg, R. A. (2000). Toward a science for and of the people: Promoting civil society through the application of developmental science. Child Development, 71, 11-20. http://dx.doi.org/10.1002/yd.20034

Lerner, R. M., Lerner, J. V., Almerigi, J. B., Theokas, Ch., Phelps, E., Gestsdottir, S., ... von Eye, A. (2005). Positive youth development, participation in community youth development programs, and community contributions of fifth grade adolescents: Findings from the first wave of the 4-H Study of Positive Youth Development. Journal of Early Adolescence, 25(1), 17-71. http://dx.doi.org/10.1002/yd.20034

Masia-Warner, C., Nangle, D. W., \& Hansen, D. J. (2006). Bringing evidence-based child mental health services to the schools: General issues and specific populations. Nebraska, University of Nebraska-Lincoln, Department of Psychology: Digital Commons. Faculty Publications, Paper 71. http://dx.doi.org/10.1002/yd.20034

Mueller, M. K., Phelps, E., Bowers, E. P., Agans, J. P., Urban, J. B., \& Lerner, R. M. (2011). Youth development program participation and intentional self-regulation skills: Contextual and individual bases of pathways to positive youth development. Journal of Adolescence, 34(6), 1115-1125. http://dx.doi.org/10.1016/j.adolescence.2011.07.010

Overton, W. F. (2014). Relational developmental systems and developmental science: A focus on methodology. In P. C. M. Molenaar, R. M. Lerner, \& K. Newell (Eds.), Handbook of developmental systems theory and methodology (pp. 19-65). New York: Guilford.

Pilkauskaite-Valickiene, R. (2015). The Role of Character, Confidence, and Connection on Contribution and Subjective Well-being. Procedia-Social and Behavioral Sciences, 197, 265-270. http://dx.doi.org/ 10.1016/j.sbspro.2015.07.134

Ravens-Sieberer, U., Gosch, A., Rajmil, L., Erhart, M., Bruil, J., Power, M., ... \& Kilroe, J. (2008). The KIDSCREEN-52 Quality of Life Measure for Children and Adolescents: Psychometric Results from a Cross-Cultural Survey in 13 European Countries. Value in Health, 11(4), 645-658. http://dx.doi.org/10.1007/s00787-008-1003-2

Rhodes, J. E., \& Roffman, J. G. (2003). Relationship-based interventions: The impact of mentoring and apprenticeship on youth development. In F. Jacobs, D. Wertlieb, \& R. M. Lerner (Eds.), Handbook of applied developmental science: Promoting positive child, adolescent, and family development through research, policies, and programs: Vol. 2. Enhancing the life chances of youth and families: Public service systems and public policy perspectives (pp. 225-236). Thousand Oaks, CA: Sage.

Roth, J. L., \& Brooks-Gunn, J. (2003a). What exactly is a youth development program? Answers from research $\begin{array}{lllll}\text { and } \quad \text { practice. } & \text { Applied }\end{array}$ http://dx.doi.org/10.1207/S1532480XADS0702_6

Roth, J. L., \& Brooks-Gunn, J. (2003b). Youth development programs: Risk, prevention and policy. Journal of Adolescent Health, 32(3), 170-182. http://dx.doi.org/10.1007/s00787-008-1003-2

Scales, P., Benson, P., Leffert, N., \& Blyth, D. A. (2000). The contribution of developmental assets to the prediction of thriving among adolescents. Applied Developmental Science, 4, 27-46. http://dx.doi.org/10.1007/s00787-008-1003-2

Schwartz, S. J., Pantin, H., Coatsworth, J. D., \& Szapocznik, J. (2007). Addressing the challenges and opportunities of today's youth: Toward an integrative model and its implications for research and intervention. Journal of Primary Prevention, 28(2), 117-144. http://dx.doi.org/10.1007/s10935-007-0084-x

Shek, D. T. L., \& Sun, R. C. F. (2010). Effectiveness of the tier 1 program of project P.A.T.H.S.: Findings based on three years of program implementation. The Scientific World Journal, 10, 1509-1519. http://dx.doi.org/10.1100/tsw.2010.122 
Statistics Lithuania. (2013). Statistical database. Vilnius, Statistics Lithuania (http://www.stat.gov.lt/, accessed 20 September 2015)

Truskauskaitè-Kunevičienė, I., Kaniušonytè, G., \& Žukauskienė, R. (2014). What does it mean to "contribute" in an Eastern-European context? The development and psychometrical evaluation of the new scale. In Conference Paper, SRCD's Special Topic Meeting "Positive Youth Development (PYD) in the Context of the Global Recession”. Prague, Czech Republic.

White, D. J. (2009). The effect of youth participatory evaluation and youth community action training on positive youth development (Doctoral dissertation).

Zaborskis, A., \& Sirvyte, D. (2015). Familial determinants of current smoking among adolescents of Lithuania: A cross-sectional survey 2014. BMC public health, 15(1), 889. http://dx.doi.org/10.1186/s12889-015-2230-3

Zaborskis, A., \& Vareikiene, I. (2007). School bullying and its association with health and lifestyle among schoolchildren. Medicina (Kaunas, Lithuania), 44(3), 232-239.

\section{Copyrights}

Copyright for this article is retained by the author(s), with first publication rights granted to the journal.

This is an open-access article distributed under the terms and conditions of the Creative Commons Attribution license (http://creativecommons.org/licenses/by/3.0/). 